\title{
Alzheimer's disease and language impairments: social intervention and medical treatment
}

\author{
This article was published in the following Dove Press journal: \\ Clinical Interventions in Aging \\ 27 August 2015 \\ Number of times this article has been viewed
}

\section{Blanka Klimova' \\ Petra Maresova ${ }^{2}$ \\ Martin Valis ${ }^{3}$ \\ Jakub Hort ${ }^{4,5}$ \\ Kamil Kuca ${ }^{6,7}$}

'Department of Applied Linguistics, ${ }^{2}$ Department of Economics, Faculty of Informatics and Management, University of Hradec Kralove, ${ }^{3}$ Department of Neurology, Faculty of Medicine in Hradec Kralove and University Hospital Hradec Kralove, Charles University in Prague, Hradec Kralove, ${ }^{4}$ Department of Neurology, Second Faculty of Medicine, Charles University in Prague and Motol University Hospital, Prague, ${ }^{5}$ International Clinical Research Center, St Anne's University Hospital Brno, Brno, ${ }^{6}$ Center for Basic and Applied Research, Faculty of Informatics and Management, University of Hradec Kralove, ${ }^{7}$ Biomedical Research Center, University Hospital Hradec Kralove, Hradec Kralove, Czech Republic
Correspondence: Kamil Kuca Biomedical Research Center, University Hospital Hradec Kralove, Sokolska 58I, Hradec Kralove, Czech Republic Tel +420603289 I66 Email kamil.kuca@fnhk.cz

\begin{abstract}
Communication is very important for people to be successfully integrated into social environment and make and maintain relationship. Particularly, language difficulties lead to social exclusion of the people affected with Alzheimer's disease (AD) and contribute to a significant decrease in the quality of their life and also have a big impact on their family members who in most cases become their caregivers who need to communicate with their loved ones in order to meet their needs. Therefore, the goal of this study is to describe language impairments in the individual phases of $\mathrm{AD}$ and discuss their improvement with respect to $\mathrm{AD}$ on the basis of literature review. The authors of this article use traditional research methods in order to achieve the goal set mentioned earlier. First, a method of literature review of available sources describing language impairments in the individual phases of AD is exploited. Second, to show how informal caregivers and relevant drugs can successfully intervene in the improvement of these language impairments, a method of comparison of different research studies exploring such social intervention and medical treatment is used.
\end{abstract}

Keywords: Alzheimer's disease, language impairments, social intervention, strategies, caregivers, clinical drugs

\section{Introduction}

Current demographic development, particularly in the developed countries, and also at a global level, is characteristic for its aging population. According to Organization for Economic Cooperation and Development (OECD) forecasts, in the following 35 years, almost a triple increase of population aged 80 and above and almost a double increase of people older than 65 years is expected in a current stable or slightly decreasing number of population in the productive age. ${ }^{1}$

Therefore, a considerable increase in the number of people with dementia is also expected in the future. The most frequent form of dementia is Alzheimer's disease (AD). The International Classification of Diseases characterizes AD as follows:

It is deterioration of memory and thinking which gradually affect self-sufficiency in daily activities. Memory is affected in all its parts and its disorder is connected with disorders of behavior and thinking. ${ }^{2}$

This disease is the principal degenerative disease of brain of unknown etiology with characteristic neuropathological and neurochemical features. This disease is divided into the following three main phases: ${ }^{2}$ the early phase (mild), in which manifestation of this disease is seen in the decline of short- and medium-term memory; the middle (moderate) phase, which is specific for its memory loss and worsening of speech skills. ${ }^{3,4}$ In the late (severe) phase, there are difficulties with food intake, walking, or recognizing relatives and friends. This is the division followed by the authors of this article. Nevertheless, there exists another classification, which divides this disease 
into preclinical $\mathrm{AD}$, mild cognitive impairment due to $\mathrm{AD}$, and dementia due to AD. ${ }^{5,6}$

\section{Early (mild) phase}

In the early phase, AD first affects the memory. It is mainly the short- and medium-term memory that is affected. The speech is usually fluent, but patients sometimes have difficulties in finding the right word. ${ }^{7}$ These limited abilities can lead to the patient's isolation. Moreover, people in this period have moderate disorders in the area of everyday activities, particularly in the area of their professional life or in executing more complex activities. ${ }^{7}$ The first behavioral symptoms can appear such as depression or anxiety, which are connected with the fact that these AD patients are aware of their own deterioration, and consequently, they feel frustrated. ${ }^{8}$ Other behavioral symptoms might include apathy, a loss of interest, fear, or sadness. In the early phase, these people are still self-sufficient, and therefore, their institutionalization is not necessary, which improves the quality of their lives. ${ }^{9}$

\section{Middle (moderate) phase}

This phase is much more serious, and it is the longest period of all three phases. It can last from 2 years to 10 years. The affected person is not able to remember his/her thoughts for such a period to be able to express them in words, which makes his/her communication less possible. Conversation with such a person is also impaired by the fact that this person is not able to adequately react to questions. The AD patient does not understand everything during the conversation, and $\mathrm{s} /$ he cannot express his/her thoughts. Sometimes this person can start speaking his/her native language which s/he did not use for long, or s/he can repeat certain sounds, words, or sentences. ${ }^{10}$ The reason is that $\mathrm{s} /$ he tries to make himself understood. Furthermore, s/he has disorders of attention and reduced verbal, mathematical, reading, and writing skills. ${ }^{11}$ In the moderate period, s/he suffers from disorientation not only in the unknown but also in the familiar environment. In fact, it is the environment in which s/he lives. Moreover, s/ he can be disoriented in time and space. Psychotic symptoms such as delusion and hallucination are frequent. ${ }^{12}$

\section{Late (severe) phase}

In this phase the damage spreads into the frontal lobe. As this happens, the person is not able to act adequately. In this final phase, all nerve cells of the brain apart from the gray matter, which controls motoric and visual functions, are damaged. Memory is impaired, but certain memories can be still recalled with the help of photos, which can bring very nice feelings. Communication is very difficult; sometimes, it is not possible to recognize to what extent the person can understand what is said to him. ${ }^{13}$ The AD patient lacks a skill of judgment, logical reasoning, and social skills. This period usually lasts $1-3$ years. The patients mostly die of intercurrent diseases such as bronchopneumonia or other diseases, which could be otherwise curable. Other causes of death are injuries and their consequences. ${ }^{10}$ As discussed earlier, communication in connection with dementia is quite important. ${ }^{14}$ Communication is important in many ways. The skill of communication is a must for a person to be successfully integrated into one's social environment and make and maintain relationship. ${ }^{15}$ During communication one passes his messages to other people and receives their messages. However, this ability is impaired in people with AD as a consequence of this disease. ${ }^{16}$

The issue of language impairments is considered in connection with medical treatment and social aspects. In 2009, the European Commission published the resolution in which all the European Union countries (ie, the developed European economies) ${ }^{18}$ are recommended to set national strategic plans in their struggle against AD. The main parts of these strategies are research and development in the area of medical treatment ${ }^{17}$ and social issues, which seem to be insufficient because there is a lack of awareness of this disease. In addition, a clear need for improved understanding of AD is required and good practices such as financing or relevant therapies should be shared throughout all European Union countries. Moreover, focus should also be on the rights of people suffering from cognitive dysfunctionality. ${ }^{18}$

\section{Methods}

The authors of this article use traditional research methods in order to describe language impairments in the individual phases of $\mathrm{AD}$ and discuss possibilities for their improvement with respect to AD. Therefore, first, a method of literature review of available sources describing language impairments in the individual phases of AD is exploited. Second, to show how informal caregivers and relevant drugs can successfully intervene in the improvement of these language impairments, a method of comparison of different research studies exploring such social intervention and medical treatment is used (Figure 1).

The selection criterion of the research studies was based on the research topics (ie, language impairments, social intervention, and medical treatment with respect to AD) found in the research articles, predominantly in the 


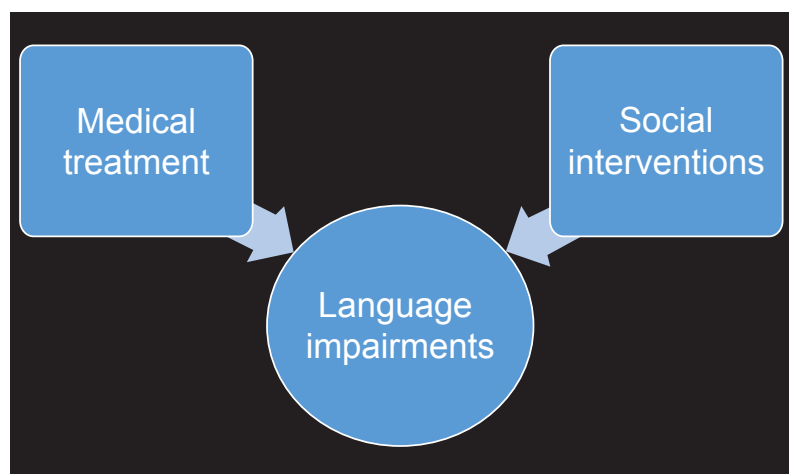

Figure I Exploration of research studies.

peer-review articles from the Web of Science for the period from 1990 up to the present time. These research studies were classified according to their relevance. The keywords are as follows:

- language impairments AND Alzheimer Disease (the number of results 1,358 )

- social intervention AND Alzheimer Disease (the number of results 702)

- medical treatment AND Alzheimer Disease (the number of results 6,615).

The authors researched the first 50 studies and their relevance to the topic. Most of the sources referred to $\mathrm{AD}$ drugs. With respect to the focus of this article, these studies were particularly used for a basic specification of drugs in the individual stages of AD. However, most of the studies discuss the explored issues within the context of individual countries, whose comparison is not the purpose of this article. The main focus of this article is to discuss the principle research trends and suggest the direction in the treatment of these issues.

\section{Language impairments in AD}

Language impairments are usually one of the first cognitive signs of the onset of AD. Specifically, they are caused by a decrease of sociolinguistic aspects. ${ }^{16}$ These include the meaning of words, difficulties with finding a relevant word, naming, and word comprehension. Consequently, but inevitably, it results in worsening of language social situations. This means that the AD patients talk too much at inappropriate times, or they might speak too loudly, repeat the same thoughts many times, or they simply digress from the topic. However, researchers in this filed ${ }^{19,20}$ assume that these sociolinguistic aspects considerably contribute to difficulties in the conversation flow, and thus lower cognitive abilities of the affected people.
Table I Language impairments in the individual phases of Alzheimer's disease

\begin{tabular}{|c|c|c|}
\hline $\begin{array}{l}\text { Communication } \\
\text { skills }\end{array}$ & Early period & $\begin{array}{l}\text { Mild and } \\
\text { severe periods }\end{array}$ \\
\hline Communication & Flowing, smooth & $\begin{array}{l}\text { Nonflowing, } \\
\text { neologism }\end{array}$ \\
\hline Repetition & Preserved & Impaired \\
\hline Identifying & Slightly impaired & Impaired \\
\hline $\begin{array}{l}\text { Understanding the } \\
\text { meaning of words }\end{array}$ & Preserved & Impaired \\
\hline $\begin{array}{l}\text { Understanding } \\
\text { of sentences }\end{array}$ & Preserved & Impaired \\
\hline Skills of reading & Preserved & Impaired \\
\hline Skills of writing & Preserved & Impaired \\
\hline $\begin{array}{l}\text { Words, phrases } \\
\text { (meaning) }\end{array}$ & $\begin{array}{l}\text { Preserved for known words } \\
\text { or phrases; impaired for } \\
\text { less familiar words and phrases }\end{array}$ & Preserved \\
\hline
\end{tabular}

In the first phase of $\mathrm{AD}$, patients usually have relatively small language problems, which are predominantly connected with lexical-semantic language difficulties such as naming the things or being vague in what they want to say. Thus, one can speak about empty speech (eg, "The thing is over there, you know"), although the speech is phonologically, morphologically, and syntactically perfectly structured. According to Manenti et al, ${ }^{21}$ some of these insufficiencies may be caused by malfunction in nonlinguistic areas, for example, in paying less attention and self-control. In the moderate and severe phases of $\mathrm{AD}$, there is a rapid increase of a lack of verbal fluency, which usually results in breakdown of comprehension. Table 1 presents an overview of the main language impairments in the individual phases of $\mathrm{AD}$.

On the one side, research studies ${ }^{22-24}$ also show that AD patients with higher education usually experience a worse language deficit than the patients with lower education. On the other side, there are studies that claim the very opposite. ${ }^{25}$ Not surprisingly, AD female patients usually perform better than males, ${ }^{26}$ although statistically they are more frequently affected with AD than males. ${ }^{27}$

\section{Social intervention in AD language difficulties}

As it can be seen in Table 1, language comprehension of the AD patients particularly worsens during the moderate and severe phases of $\mathrm{AD}$. The affected people are not able to express themselves and thus communicate with their family members, relatives, or friends. They find themselves in total social exclusion. Furthermore, the loss of communication also has an enormous impact on their quality of life and considerably contributes to their and their caregiver's burden. ${ }^{16,18,28}$ 
In $80 \%$ cases, caregivers are family members ${ }^{27}$ whose life then undergoes significant changes as well. As Maresova et $\mathrm{al}^{17}$ pointed out, these caregivers are mostly middle-aged people with a lot of other responsibilities. Sometimes, they even give up their jobs in order to help their loved ones. Furthermore, besides losing their regular income, they often lose their relationship, free time, and eventually, they end up in social isolation. This consequently affects their health as well. They usually have sleep problems and behavioral disorders. In addition, these informal caregivers report communication breakdown with their loved ones, which often results in worsening their mutual relations and contacts. ${ }^{16}$ Therefore, different communicative strategies have been developed by professional organizations in order to lower caregiver's burden as far as the language difficulties are concerned. In this process, the Association of Speech-Language Pathologists plays a key role. ${ }^{17}$ They mainly concentrate on the intellectual, speaking, and partly physical insufficiencies connected with dementia. Furthermore, they try to help these people affected with dementia to be independent, of course with respect to their abilities. They focus on training their memory, speaking, solving problems, or self-control. The association teaches these people to use different kinds of techniques to maintain their intellectual and physical skills and abilities as long as possible. They provide them with a list of the following useful techniques and strategies:

- revising the crucial words or phrases to maintain their attention;

- posing close questions to aim at an easier reply, such as Do you want an apple or an orange?, instead of What fruit would you like for your snack?;

- always trying to give clear and concise information, which would make the conversation flow easier;

- provide the patient with a written list of things and tasks to do, such as how to switch on TV or how to make a simple dinner;

- write down a diary which can help the patient to remember things easier and where he/she can keep his/her personal data;

- keep telling the patient to take drugs;

- motivate family members to participate in workshops on how to deal with $\mathrm{AD}$ patients and on how to cope with potential risks.

In addition, there exist various written guides, such as the DementiaGuide, ${ }^{6,29}$ which suggest that caregivers should be always calm when they communicate with their loved ones; provide clues to what they are trying to say by pointing to an object or bringing the word into conversation instead of interrupting them, or simply telling them the word they are looking for; think of the environment in which communication is done because these affected people usually prefer face-to-face communication in a quiet environment; avoid speaking when the patient is tired; or encourage the patients to talk by asking them about their daily activities.

\section{Medical treatment}

The current possibilities of treatment solve just the symptoms of this disease. There exist two classes of drugs with differing mechanisms of action that are licensed for the treatment of AD. These are as follows: ${ }^{30,31}$

- acetyl cholinesterase inhibitors for the treatment of mild and moderate AD (donepezil, galantamine, and rivastigmine); and

- the $N$-methyl-D-aspartate receptor antagonist, memantine, for the treatment of moderate-to-severe AD.

These drugs do not prolong patients' survival, but they are able to delay the most serious phases of $\mathrm{AD}$, increase memory, quality of life and self-sufficiency of AD patients, and lower caregivers' burden. A number of other drugs also influence behavioral disorders and mood (antidepressants or neuroleptic drugs), sleeping disorders, and other symptoms.

\section{Effect of drugs with respect to language impairments in AD}

Overall, there are $\sim 81$ drugs for AD treatment. However, only four of them have been clinically approved so far. There are research studies that prove a positive impact of these clinical drugs on AD treatment, in this case, on language impairments. ${ }^{32}$ Therefore, these clinical drugs and their effect on language impairments are discussed.

\section{Memantine}

Ferris et $\mathrm{al}^{33}$ assessed the treatment effects of memantine on language communication, particularly in the later stages of AD. They used the Severe Impairment Battery-Language scale. Altogether, they clinically tested 801 people with daily doses of memantine $(20 \mathrm{mg})$ or placebo $(20 \mathrm{mg})$. They discovered that especially memantine had a very positive effect on the patients suffering from serious language difficulties. They found out that the mean change from baseline in Severe Impairment Battery-Language score at 12 weeks, 24 weeks, and 28 weeks was significantly higher in case of memantine than placebo $(P<0.0001, P=0.0182)$. This was particularly true for the patients with language disorders. These patients improved, while only very few worsened. 
Thus, they concluded that memantine could be a solution to the language difficulties and use for their treatment, specifically for the patients with serious language impairment.

\section{Donepezil}

Similarly, donepezil and placebo were clinically tested for language impairments. The daily dose of these drugs was $10 \mathrm{mg}$. The AD patients were tested for six consecutive months. Once again there was a considerable favor for the treatment of donepezil than placebo. ${ }^{34-37}$ All the patients treated with donepezil experienced much more positive effects on their language communication and showed less language impairments after this treatment. ${ }^{38}$ In addition, research study by Ferris et $\mathrm{al}^{39}$ proved that a higher dose of donepezil (23 mg) a day after 6 months had showed a 0.8-point improvement over the so far used lower dose $(10 \mathrm{mg})$ of this drug. The researchers believe that this might have been caused by the increased dose of this drug accelerating higher acetyl cholinesterase reserve, which consequently raises cholinergic performance of the brain areas connected with language. They also assume that another reason might have consisted in the enforced impact of higher dose of donepezil (23 mg) on the brain areas connected with recollection or concentration.

\section{Rivastigmine}

Also rivastigmine has been used for the treatment of language impairments since 2000. Farlow et $\mathrm{al}^{40}$ examined the effect of rivastigmine on cognitive functions at patients with mildto-moderate $\mathrm{AD}$ for the period of 26 weeks in four different random trials. The patients who were taking $6-12 \mathrm{mg}$ of this drug a day had far better results than those taking the same dose of placebo. It mainly concerned language functions $(P<0.001)$, praxis $(P<0.001)$, and memory $(P<0.0001)$. However, other research studies ${ }^{41}$ have not showed any considerable differences between the treatment of rivastigmine and placebo. In addition, both drugs have not proved any substantial benefits for the language impairments, particularly in the early stages of AD.

\section{Galantamine}

This approved clinical drug has proved to be relatively successful over placebo in six of the nine Severe Impairment Battery domains, particularly in the area of memory $(P<0.006)$, praxis $(P<0.010)$, and visuospatial ability $(P<0.002) .{ }^{42}$ Nevertheless, in other clinical research studies, this drug has not showed any considerable improvement in the language functions with $\mathrm{AD}$ patients when compared again with the treatment by placebo. ${ }^{16}$

\section{Discussion}

As the findings show, the AD patients already in the first phase need professional care, which can be provided by both professionals - in this case, by speech therapist - and family members/informal caregivers who should be trained on how to communicate with their affected loved ones. As the study by Clare and Woods $(2001)^{43}$ proves, helping AD patients in the first phase of this disease might increase and keep their speaking skills and self-reliance for a longer period, and thus eliminate for a certain time their social exclusion and increased level of dependence on their caregivers. This is also confirmed by general trends on communication strategies in $\mathrm{AD}$. According to Zientz et al, ${ }^{44}$ raising caregivers' awareness about certain speaking techniques and strategies can bring the following benefits:

- better interaction between the patient and his/her counterpart;

- keeping language skills of the affected people;

- improved quality of life of AD patients;

- reduced or increased caregiver burden because they take on a higher responsibility in the interaction with $\mathrm{AD}$ patients;

- increase in the caregivers' knowledge of AD and their understanding of communication breakdown.

In addition, $\mathrm{AD}$ patients should be given clinical drugs because clinical research studies show their positive effect on the delaying of language impairments. ${ }^{16}$ These drugs should be, however, given with respect to the complex patient's state in the individual stages of AD. Thus, donepezil is intended for the treatment in all AD stages. It is taken as a pill once a day at bedtime. Patients should start taking a $5 \mathrm{mg}$ dose a day and after 1 month increase the dose to $10 \mathrm{mg}$ if they need it. Moreover, patients tolerate this drug well. Memantine is intended for the treatment of moderateto-severe AD. It can be taken as tablets (10-20 mg) or syrup $(10 \mathrm{mg})$ with or without meals once a day. Patients should start taking a $5 \mathrm{mg}$ dose and increase it by $5 \mathrm{mg}$ every week up to $20 \mathrm{mg}$ per day. However, this drug has a few side effects such as headache, puzzlement, distress, or anxiety. Both rivastigmine and galantamine are meant for the treatment of mild-to-moderate AD. Rivastigmine is taken two times a day, in the morning and in the evening with meals. Patients should start at $3 \mathrm{mg}$ a day in two split doses and after 14 days increase the dose to between $6 \mathrm{mg}$ and $12 \mathrm{mg}$ a day. Galantamine is taken as tablets or drops, $8 \mathrm{mg}$ once a day for a month, and then patients should increase the dose to $16 \mathrm{mg}$ a day for another 4 weeks. The maximum dose is $24 \mathrm{mg}$ a day. ${ }^{45,46}$ 
Although there many strategies and techniques both for the patients and caregivers and the clinical drugs the patients can take, there is also a chance to prevent it before AD language impairments arrive. This can be done by eating enough fruit and vegetables, ${ }^{47}$ doing physical exercises, ${ }^{48-50}$ or solving various crosswords and quizzes on a daily basis. ${ }^{51}$ But as far as the language difficulties are concerned, one should also try to master at least another (foreign) language because research studies show that lifelong bilingualism confers protection against the onset of AD. ${ }^{52}$ For instance, Bialystok et al ${ }^{53,54}$ conducted research of the hospital records of monolingual and bilingual people who were affected with dementia and discovered that the bilingual people fell ill with dementia 3-4 years later than the monolingual patients. Moreover, speaking more than one language does not seem to be connected to education, occupational status, or immigration. As Craik et al ${ }^{52}$ add, bilingualism thus seems to contribute to cognitive reserve, which acts to compensate for the effects of accumulated neuropathology.

In addition, early diagnosis of cognitive decline, including the essential language functions, can be done by establishing accurate and sensitive assessment tools that can screen cognitive functions. ${ }^{55,56}$

\section{Conclusion}

The findings of this study show the effect of AD on language functions in each of the three phases of AD. Despite the modest clinical effects of existing treatments of AD such as cholinesterase inhibitors and memantine, ${ }^{57,58}$ on the basis of literature review, the authors of this article conclude that the focused social intervention in the form of well-trained caregivers and proven medical treatment can successfully contribute to the delay of some of the most serious effects of AD such as language impairments. The authors also suggest that more longitudinal extensive clinical trials discovering effect of social intervention and medical treatment on delaying the development of AD should be conducted. This study can also serve as enrichment of a few review studies on this topic.

\section{Acknowledgments}

This research was supported by the grant PRVOUK: P37/08, Project Excellence 2015 (University of Hradec Kralove, Faculty of Informatics and Management), Long-term development plan of the University of Hradec Kralove.

\section{Disclosure}

The authors report no conflicts of interest in this work.

\section{References}

1. OECD. Database Data: Population Development, Historical Data and Forecast; 2015 [cited June 9, 2015]. Available from: http://stats.oecd. org/\#. Accessed April 20, 2015.

2. WHO. International Classification of Diseases (ICD); 1994 [cited June 9, 2015]. Available from: http://www.who.int/classifications/icd/en/ Accessed April 20, 2015.

3. Stages of Alzheimer's. Alzheimer's Association; 2015 [cited June 9, 2015]. Available from: http://www.alz.org/alzheimers_disease_stages_ of_alzheimers.asp. Accessed April 20, 2015.

4. Klímová B, Marešová $P$, Kuča $K$. Assistive technologies for language disorders in dementia [in review].

5. Sperling RA, Aisen PS, Beckett LA, et al. Toward defining the preclinical stages of Alzheimer's disease: recommendations from the National Institute on Aging-Alzheimer's Association workgroups on diagnostic guidelines for Alzheimer's disease. Alzheimers Dement. 2011;7(3): 280-292.

6. Alzheimer's Association. Alzheimer's Disease Facts and Figures. Alzheimer's and Dementia; 2012 [cited June 9, 2015]. Available from: http:// www.alz.org/downloads/Facts_Figures_2012.pdf. Accessed April 20, 2015.

7. Dementia of the Alzheimer's Type - Description of Stages. Website of Charles F. and Joanne Knight Alzheimer's Disease Research Center (Knight ADRC), Washington University School of Medicine in St Louis, Missouri, USA; 2003 [cited June 9, 2015]. Available from: http://knightadrc.wustl.edu/About_Us/PDFs/Stages_of_AD.pdf. Accessed April 20, 2015.

8. National Institute on Aging. Alzheimer's Disease. Unraveling 2 the Mystery. US; 2012 [cited Jun 9, 2015]. Available from: https://www.nia. nih.gov/sites/default/files/alzheimers_disease_unraveling_the_mystery. pdf. Accessed April 20, 2015.

9. Frederiks C, Hofmann MT, Reichard T. Advances in diagnosis and treatment of Alzheimer's disease. Hosp Physician. 2002;5:47-54.

10. Macoir J, Laforce R Jr, Monetta L, Wilson M. Language deficits in major forms of dementia and primary progressive aphasias: an update according to new diagnostic criteria. Geriatr Psychol Neuropsychiatr Vieil. 2014;12(2):199-208.

11. Shivanand P. Review on Alzheimer's disease: its cause, symptoms, and treatment at worldwide. Int J Appl Biol Pharm Technol. 2009;1(1): $112-120$.

12. Eliopoulos C, Carson VB, Varcarolis E. Cognitive disorders. Evolve Resources for Varcarolis' Foundations of Psychiatric Mental Health Nursing. St Louis, MO: Saunders Elsevier; 2006.

13. Pekkala S. Semantic Fluency in Mild and Moderate Alzheimer's Disease. Helsinki: Hakapaino Oy; 2004.

14. Orange JB, Colton-Hudson A. Enhancing communication in dementia of the Alzheimer's type. Top Geriatr Rehabil. 1998;14(2):56-75.

15. Savundranayagam ME, Ryan EB, Anas AP, Orange JB. Communication and dementia: staff perceptions of conversational strategies. Clin Gerontol. 2007;31(2):47-63.

16. Ferris SH, Farlow M. Language impairment in Alzheimer's disease and benefits of acetylcholinesterase inhibitors. Clin Interv Aging. 2013;8: $1007-1014$

17. Maresova P, Klimova B, Kuca K. Alzheimer's disease: cost cuts call for novel drugs development and national strategy. Ceska A Slovenska Farmacie. 2015;64:25-30.

18. EC. European Initiative on Alzheimer's Disease and Other Dementias, Brussels; 2009 [cited June 9, 2015]. Available from: http://ec.europa. $\mathrm{eu} / \mathrm{health} / \mathrm{ph}$ _information/dissemination/documents/com2009_380_ en.pdf. Accessed April 20, 2015.

19. Savundranayagam MY, Hummert ML, Montgomery RJ. Investigating the effects of communication problems on caregiver burden. J Gerontol B Psychol Sci Soc Sci. 2005;60(1):S48-S55.

20. Ripich DN. Functional communication with AD patients: a caregiver training program. Alzheimer Dis Assoc Disord. 1994;8(3):95-109.

21. Manenti R, Repetto C, Bentrovato S, Marcone A, Bates E, Cappa SF. The effects of ageing and Alzheimer's disease on semantic and gender priming. Brain. 2004;127(10):2299-2306. 
22. Tang-Wai DF, Graham NL. Assessment of language function in dementia. Geriatr Aging. 2008;11:103-110.

23. Amieva H, Jacqmin-Gadda H, Orgogozo JM, et al. The 9-year cognitive decline before dementia of the Alzheimer type: a prospective population-based study. Brain. 2005;128:1093-1101.

24. Laws KR, Duncan A, Gale TM. "Normal' semantic-phonemic fluency discrepancy in Alzheimer's disease? A meta-analytic study. Cortex. 2010; 46:595-601.

25. Stern Y, Albert S, Tang MX, Tsai WY. Rate of memory decline in AD is related to education and occupation: cognitive reserve? Neurology. 1999;53:1942-1957.

26. Fritsch T, McClendon MJ, Smyth KA, Ogrocki PK. Effects of educational attainment and occupational status on cognitive and functional decline in persons with Alzheimer-type dementia. Int J Geriatr Psychiatry. 2002;1:347-363.

27. Capitani E, Laiacona M, Basso A. Phonetically cued word-fluency, gender differences and aging: a reappraisal. Cortex. 1998;34:779-783.

28. Arrighi HM, Neumann PJ, Lieberburg IM, Townsend RJ. Lethality of Alzheimer disease and its impact on nursing home placement. Alzheimer Dis Assoc Disord. 2010;24(1):90-95.

29. DementiaGuide. 2015 [cited June 9, 2015]. Available from: http:// www.dementiaguide.com/symptomlibrary/memorylanguage/language_ difficulty/managementstrategies/. Accessed April 20, 2015.

30. Zemek F, Drtinova L, Nepovimova E, et al. Outcomes of Alzheimer's disease therapy with acetylcholinesterase inhibitors and memantine. Expert Opin Drug Saf. 2014;13(6):759-774.

31. Nepovimova E, Uliassi E, Korabecny J, et al. Multitarget drug design strategy: quinone-tacrine hybrids designed to block amyloid- $\beta$ aggregation and to exert anticholinesterase and antioxidant effects. $J$ Med Chem. 2014;57(20):8576-8589.

32. Hilari K, Needle JJ, Harrison KL. What are the important factors in health-related quality of life for people with aphasia? A systematic review. Arch Phys Med Rehabil. 2012;93(suppl 1):86-95.

33. Ferris $\mathrm{S}$, Ihl R, Robert $\mathrm{P}$, et al. Treatment effects of memantine on language in moderate to severe Alzheimer's disease patients. Alzheimers Dement. 2009;5:369-374.

34. Winblad B, Kilander L, Eriksson S, et al; Severe Alzheimer's Disease Study Group. Donepezil in patients with severe Alzheimer's disease: doubleblind, parallel-group, placebo-controlled study. Lancet. 2006;367(9516): 1057-1065.

35. Black SE, Doody R, Li H, et al. Donepezil preserves cognition and global function in patients with severe Alzheimer disease. Neurology. 2007;69(5):459-469.

36. Cummings J, Jones R, Wilkinson D, et al. Effect of donepezil on cognition in severe Alzheimer's disease: a pooled data analysis. J Alzheimers Dis. 2010;21(3):843-851.

37. Winblad B, Black SE, Homma A, et al. Donepezil treatment in severe Alzheimer's disease: a pooled analysis of three clinical trials. Curr Med Res Opin. 2009;25(11):2577-2587.

38. Schwam E, Xu Y. Cognition and function in Alzheimer's disease: identifying the transitions from moderate to severe disease. Dement Geriatr Cogn Disord. 2010;29(4):309-316.

39. Ferris SH, Schmitt FA, Saxton J, et al. Analyzing the impact of $23 \mathrm{mg} /$ day donepezil on language dysfunction in moderate to severe Alzheimer's disease. Alzheimers Res Ther. 2011;3(3):22.
40. Farlow MR, Cummings JL, Olin JT, Meng X. Effects of oral rivastigmine on cognitive domains in mild-to-moderate Alzheimer's disease. Am J Alzheimers Dis Other Demen. 2010;25(4):347-352.

41. Grossberg GT, Schmitt FA, Meng X, Tekin S, Olin J. Reviews: effects of transdermal rivastigmine on ADAS-cog items in mild-to-moderate Alzheimer's disease. Am J Alzheimers Dis Other Demen. 2010;25(8): 627-633.

42. Burns A, Bernabei R, Bullock R, et al. Safety and efficacy of galantamine (Reminyl) in severe Alzheimer's disease (the SERAD study): a randomised, placebo-controlled, double-blind trial. Lancet Neurol. 2009; 8(1):39.

43. Clare L, Woods R. Cognitive rehabilitation in dementia. Neuropsychol Rehabil. 2001;11:193-517.

44. Zientz J, Rackley A, Chapman SB, et al. Evidence-based practice recommendations for dementia: educating caregivers on Alzheimer's disease and training communication strategies. $J$ Med Speech Lang Pathol. 2007;15(1):liii-lxiv.

45. Drug Treatment for Alzheimer's Disease; 2015 [cited June 9, 2015]. Available from: http://www.alzheimers.org.uk/site/scripts/ documents_info.php?documentID=147. Accessed April 20, 2015.

46. Mayo Clinic Staff. Alzheimer's: Drugs Help Manage Symptoms; 2014 [cited June 9, 2015]. Available from: http://www.mayoclinic. org/diseases-conditions/alzheimers-disease/in-depth/a\%20lzheimers/ art-20048103. Accessed April 20, 2015.

47. Pope SK, Shue VM, Beck C. Will a healthy lifestyle help prevent Alzheimer's disease. Annu Rev Public Health. 2003;24:111-132.

48. Kivipelto M, Solomon A. Alzheimer's disease - the ways of prevention. J Nutr Health Aging. 2007;12:89-94.

49. Radak Z, Hart N, Sarga L, et al. Exercise plays a preventive role against Alzheimer's disease. J Alzheimers Dis. 2010;20:777-783.

50. Rovio S, Kåreholt I, Helkala EL, et al. Leisure-time physical activity at midlife and the risk of dementia and Alzheimer's disease. Lancet Neurol. 2005;4:705-711.

51. Joe Verghese MD, Richard B, Lipton MD. Leisure Activities and the risk of dementia in the elderly. N Engl J Med. 2003;348:2508-2516.

52. Craik FIM, Bialystock E, Freedman M. Delaying the onset of Alzheimer's disease. Bilingualism as a form of cognitive reserve. Neurology. 2010;75(19):1726-1729.

53. Bialystok E, Craik FIM, Luk G. Bilingualism: consequences for mind and brain. Trends Cogn Sci. 2012;16(4):240-250.

54. Bialystok E, Craik FIM, Freedman M. Bilingualism as a protection against the onset of symptoms of dementia. Neuropsychologia. 2007; 45:459-464.

55. Soares FC, de Oliveira TC, de Macedo LD, et al. CANTAB object recognition and language tests to detect aging cognitive decline: an exploratory comparative study. Clin Interv Aging. 2015;10:37-48.

56. Vestal L, Smith-Olinde L, Hicks G, Hutton T, Hart J Jr. Efficacy of language assessment in Alzheimer's disease: comparing in-person examination and telemedicine. Clin Interv Aging. 2006;1(4):467-471.

57. Sköldunger A, Johnell K, Winblad B, Wimo A. Mortality and treatment costs have a great impact on the cost-effectiveness of disease modifying treatment in Alzheimer's disease - a simulation study. Curr Alzheimer Res. 2013;10:207-216.

58. Soukup O, Jun D, Zdarova-Karasova J, et al. A resurrection of 7-MEOTA a comparison with tacrine. Curr Alzheimer Res. 2013;10(8):893-906.
Clinical Interventions in Aging

\section{Publish your work in this journal}

Clinical Interventions in Aging is an international, peer-reviewed journal focusing on evidence-based reports on the value or lack thereof of treatments intended to prevent or delay the onset of maladaptive correlates of aging in human beings. This journal is indexed on PubMed Central, MedLine,

\section{Dovepress}

CAS, Scopus and the Elsevier Bibliographic databases. The manuscript management system is completely online and includes a very quick and fair peer-review system, which is all easy to use. Visit http://www.dovepress. com/testimonials.php to read real quotes from published authors. 


\section{Publish your work in this journal}

Clinical Interventions in Aging is an international, peer-reviewed journal focusing on evidence-based reports on the value or lack thereof of treatments intended to prevent or delay the onset of maladaptive correlates of aging in human beings. This journal is indexed on PubMed Central, MedLine,

CAS, Scopus and the Elsevier Bibliographic databases. The manuscript management system is completely online and includes a very quick and fair peer-review system, which is all easy to use. Visit http://www.dovepress. com/testimonials.php to read real quotes from published authors.

Submit your manuscript here: http://www.dovepress.com/clinical-interventions-in-aging-journal 